Историография. Источниковедение. Археографиия

УДК [351:930.25(094)]:94(571.513).084.6»1930/1938»

ББК 79.347.1+63.3(2Рос.Хак)614-2

DOI $10.31554 / 2222-9175-2019-34-149-155$

Е. П. Мамышева, Е. Ю. Шаповал

АОКУМЕНТЫ ГОСУААРСТВЕННОГО АРХИВА
РОССИЙКОЙ ФЕАЕРАЦИИ (ГАРФ)О АЕЯТЕ ЬНОСТИ
ПРЕАСТАВИТЕАЬСТВА ХАКАССКИИ АВТОНОМНОЙ
ОБААСТИ ПРИ ВЦИК РСФСР В 1930-1932 гГ.

Представлена подборка документов Государственного архива Российской Федерации (фонд Р-1235 «Всероссийский центральный исполнительный комитет Советов рабочих, крестьянских и красноармейских депутатов»), в которых прослеживаются функции представительства Хакасской автономной области при ВЦИК РСФСР в период 1930-1932 гг. На основе архивных документов освещаются направления работы представительства по решению с союзным центром вопросов политического и экономического развития автономной области; особое внимание уделено деятельности первого полномочного представителя Хакасии при ВЦИК П.И. Гедымин-Тюдешевой.

Ключевые слова: Хакасия, автономная область, ВЦИК, представительство, П. И. Гедымин-Тюдешева, архивные документы.

E. P. Mamysheva, E. Yu. Shapoval

\title{
DOCUMENTS OF THE STATE ARCHIVE OF THE RUSSIAN FEDERATION (GARF) ABOUT THE ACTIVITIES OF THE REPRESENTATION OF THE KHAKASS AUTONOMOUS REGION IN THE CENTRAL EXECUTIVE COMMITTEE OF RSFSR IN 1930-1932
}

The article presents a selection of documents from the State Archive of the Russian Federation (R-1235 Foundation "All-Russian Central Executive Committee of Workers ', Peasants and Red Army Deputies' Councils"), which consider the functions of the representative office of the Khakass Autonomous Region under the All-Russian Central Executive Committee of the RSFSR in the period 1930-1932. On the basis of archival documents, the directions of the representation's work on solving the autonomous region's political and economic development issues with the Union Center are highlighted, special attention is paid to the activities of the first plenipotentiary representative of Khakassia at the All-Russian Central Executive Committee P. I. Gedymin-Tyudesheva.

Keywords: Khakassia, autonomous region, the All-Russian Central Executive Committee, representative office, P. I. Gedymin-Tüdesheva, archival documents.

дним из малоизученных вопросов государственного устройства националь-
ных субъектов Сибири в советское время является деятельность представительств автономий при ВЦИК РСФСР. Значение представительств в приобщении

\footnotetext{
МАМЫШЕВА Елена Петровна - доктор исторических наук, доцент, профессор кафедры истории России Федерального государственного бюджетного образовательного учреждения высшего образования «Хакасский государственный университет им. Н. Ф. Катанова» (Абакан, Россия). E-mail: sozor@ mail.ru.

ШАПОВАЛ Евгений Юрьевич - кандидат исторических наук, начальник отдела информационных архивных технологий Государственного архива Республики Бурятия (Улан-Удэ, Россия). E-mail: ewgen8282@inbox.ru.
} 
сибирских народов к советскому строительству, на наш взгляд, недооценено, притом что работа института представительств имела осязаемые результаты в отстаивании интересов автономий перед центральными органами власти и учреждениями в важнейших сферах социально-экономического и культурного развития.

Эта проблема соотносится и с функционированием в 1930-1938 гг. Представительства Хакасской автономной области при ВЦИК, становление которого раскрывается на основе документов региональных архивов Сибири лишь в отдельных публикациях [Белозерова 2008: 16-21; Мамышева 2009: 96-101; Карачакова 2005: 240-242]. Важную лепту в исследование Представительства Хакасии как государственно-правового института внес М. А. Митюков [Милюков 1986: 42-49], в аналитическом материале юриста основной акцент ставится на нормативно-правовой основе деятельности данного учреждения.

Между тем, в фондах одного из крупнейших федеральных центров по хранению документов высших органов власти страны - Государственного архива Российской Федерации отложились документы, освещающие создание и работу Представительства автономной области Хакасии при ВЦИК РСФСР [ГАРФ. Ф. 1235. Оп. 126].

В этой связи авторы ставят своей задачей показать ценность и значимость документов ГАРФ как важнейшего источника в деле изучения деятельности Представительства на начальном этапе, когда представителем Хакасской автономной области в высших партийных органах страны была П. И. Гедымин-Тюдешева.

Следует отметить, что на тот момент проблема формирования кадров руководящих работников вновь образованной области была достаточно острой, и П. И. Гедымин-Тюдешева, имевшая большой стаж партийной и государственной работы в г. Красноярске, Иркутской области и Бурят-Монгольской республике, весьма кстати вернулась в Хакасию в июне 1930 г. [1]. В рамках проводимой в 1930-е гг. политики коренизации государственного аппарата ее назначение как представительницы титульного этноса выглядело вполне логичным. Для нее же назначение явилось полной неожиданностью. Парасковья Иннокентьевна в своих воспоминаниях писала: «Мало-мало развязался язык, и ответила, что меня край послал на работу в Хакасию, а не в Москву, ибо совершенно не знала Хакасии». Несмотря на возражения Парасковьи Иннокентьевны, члены оргкомитета приняли решение о назначении ее представителем Хакасии [Мамышева 2008: 173-182].

Находясь на ответственном посту, П. И. Гедымин-Тюдешева много сил отдала развитию в автономной области промышленности, сельского хозяйства, здравоохранения, образования, организации подготовки национальных кадров в высших и средних учебных заведениях Центральной России. У нее сложились дружеские отношения с Н. К. Крупской которая неоднократно принимала ее, проявляя большой интерес к Хакасии. При содействии Н. К. Крупской Гедымин-Тюдешева добилась в Наркомате здравоохранения выделения электроаппаратуры для областной больницы, появления в Хакасии передвижных медицинских красных юрт, дома матери и ребенка, строительства в г. Абакане учительского института и мн. др. [Мамышева 2008: 173-182].

В данной подборке документов следует отметить отчет П. И. Гедымин-Тюдешевой в качестве представителя автономной области, материалы совещаний, в которых она принимала участие. В статье публикуются сведения, характеризующие начальный, организационный этап работы, который требовал согласования всех вопросов между органами власти края, автономной области и союзным центром.

Тексты документов публикуются с извлечениями и комментариями. Документы оформлены в соответствии с «Правилами издания исторических документов в СССР» (М., 1990). Заголовки к документам даны авторами публикации, в них 
применяются общепринятые сокращения, аббревиатуры названий органов государственной власти, существовавших в первые годы после образования республики, ВСНХ, ВЦИК, Наркомат и т. д.

Тексты документов переданы в соответствии с современными правилами орфографии и пунктуации, стилистические особенности документов сохранены. Погрешности текста, не имеющие смыслового значения (орфографические ошибки, опечатки и т. п.) исправлены в тексте без оговорок. Сохранены географические названия того периода. Примечания (комментарии) по содержанию публикуемых документов составлены по печатным и архивным источникам.

\section{Документ № 1 \\ Из материалов совещания работников промышленности национальных авто- номных республик и национальных автономных областей РСФСР, проходив- шего при Президиуме ВСНХ РСФСР [2]}

\section{г. Москва}

03 сентября 1931 г.

$<\ldots>$ Т[оварищ] Гедымин (Хакасия): Мне кажется, что организация труда по вовлечению национальных меньшинств в производство должна идти по двум направлениям. Во-первых, вовлечение в промышленность коренного населения и тех национальных меньшинств, которые находятся на территории АО [3], республики. В этом отношении у самого ВСНХ нет твердости в работе, по-прежнему остается механическое вовлечение в промышленность коренного населения и нацменьшинств путем вербовки, которая влечет за собой чрезмерно неприятные последствия для производства. Наши хозяйственники вербуют при помощи органов Наркомтруда. Получается, таким образом, что государственные вербовщики, и в т. ч. Наркомтруд, и соответствующие организации совершенно забывают, что для националов нужно создать соответствующие условия. Мало того, что дадите койку, умывальник, надо дать духовное. Надо приблизить коренное население к производству через производные совещания на родном языке. На наших производствах мы имеем чернорабочую силу, а квалифицированных ребят в порядке выдвижения нет.

$<\ldots>$ Гедымин (Хакасия): В докладе товарища Виноградова имеется всё на свете, а по существу ничего нет. Выпал такой большой раздел, как автономные национальные области. Это говорит за то, что аппарат ВСНХ, за исключением районного сектора, не перестроился в деле проведения ленинской национальной политики в национальных областях и республиках.

Наша область молодая, мы существуем всего 10 месяцев, и когда приходишь в наши московские наркоматы, то там делают большие глаза, которые чуть не вылезают на лоб. Не знают, что такое Хакасия. Об этом не знает и плановый отдел ВСНХ. В центре мне сказали: «Вы не волнуйтесь, рабочее питание на Алдане поставлено на «отлично». Да вы знаете, где находится Алдан и где Хакасия.

После практических указаний в районном секторе мы спустились на тот этаж, где сидит Виноградов. Начальник сектора с ним не разговаривает. Это понятно, нельзя беспокоить большого человека, ну, а если вопрос не проработан у него в аппарате? И сказали: «Приходите завтра». На завтра приходим с ориентировочными цифрами строительства на 1932 год. Нам возвращают материалы и говорят: «Мы ничего не можем сказать, наша промышленность союзного масштаба».

Мы слышали за этим столом, что не может быть деления на ваше и наше, надо BCHX самому поинтересоваться, а не отпихиваться от нас. На мой вопрос, почему ничего не говорится о Хакасии по части ее строительства, т. Виноградов ответил, что у него в числе объектов имеются те республики, точки строительства которых прошли через $\mathrm{BCHX}$ и более или менее определили свою физиономию. У меня на 
руках имеются материалы Госплана Союза по контрольным цифрам Западной Сибири. Это еще раз характеризует, как аппарат ВСНХ поворачивается к национальным областям. В этом постановлении 03.07.1931 г. говорится: «...одобрить те положения, которые выдвигает Западная Сибирь, и говорится о Минусинском бассейне».

На 15-м году Октябрьской революции наш аппарат не знает экономической географии. Дальше говорится о Минусинском комбинате, что это такое, комбинат этот находится на территории Хакасской АО. Надо работникам экономического сектора знать экономическую географию. Какие-то объекты строительства были перенесены на 1931 г., но по разным причинам не выполнены у нас, на территории ХАО, за исключением одного лесопильного механизированного завода, который работает.

Как ВСНХ РСФСР собирается в этом деле помогать, я приехала сюда в ВСНХ с плановым работником, который приехал за 5 тысяч верст. А мы включены в Урало-Кузнецкий комбинат. На днях вышло постановление правительства по нашему докладу, где написано, какие мы должны принять меры к тому, чтобы оправдать директиву партии и Советской власти, что Хакасия включена в Урало-Кузнецкий комбинат. Я хочу остановиться на тех больных вопросах, с которыми мы приехали и о которых надо было через ВСНХ кричать. Мы говорили относительного металлургического завода. Мы выдвигаем требования о начале постройки комбината в 1932 г. и требуем на предварительные работы 60 млн. рублей.

$<\ldots>$ Край предлагает истребовать пять млн. рублей и начать строительство. Будет проходить совещание. Что на этом совещании по части Хакасии мы скажем? Ничего, потому что нас не хотели слушать, нашего работника, не хотели получить те сведения, которые нужно было дать в форме директив по части составления контрольных цифр на 1932 г. и контрольных точек на II пятилетку. Этого не сделано $<\ldots>$.

[ГАРФ. Ф. 1235. Оп. 126. Д. 3. Л. 79, 187, 187об. Машинопись. Копия].

\section{Документ № 2}

\section{Справка по вопросам, относящимся к Хакасской автономной области получившим положительные решения в центральных наркоматах}

\section{г. Москва}

1931 год

Культурно-бытовые вопросы

1. Комитетом УТБ [4] ВЦИК отпущено на организацию Дома матери и ребенка. До сих пор со стороны областных организаций нет не только отчета, как израсходовались средства, но и информации о состоянии.

2. НКП [5] должен был послать бригаду в количестве двух человек по организации национального театра, набору курсантов для подготовки режиссеров из коренного населения и создания на месте актива, в жизнь не провелось, так как несмотря на телеграфные извещения, все же ответ получился с опозданием, и бригада выехала в другой район.

3. НКП была предоставлена броня в разные учебные заведения (48 мест), как использовались места, неизвестно, несмотря на запросы Представительства об итогах набора, таковых нет. Надо полагать, что использование мест прошло неудовлетворительно, например, из предоставленных мест в центральный медтехникум из четырех использовано одно, на колхозные курсы было дано 14 мест, использовано только 50 \%. Отмечается то обстоятельство, что выделение броней проходит весьма несвоевременно, брони даются за две недели до начала занятий. НКП не учитывает дальность расстояния и связь на местах. Послан бригадир по культштурму в помощь Хакасии (июнь-июль). 
Историография. Источниковедение. Археография

4. Комитетом по делам печати и полиграфтрестом отпущено 75 тыс. рублей на усиление нац[онального] издательства и газеты, в т. ч. 55 тыс. рублей на подготовку к строительству новой типографии и 200 тыс. рублей на 1932 г. по капитальному строительству и оборудованию типографии. Предусмотрена новая газета «Комсомольская».

Сельское хозяйство и другое

1. Системами «Скотовод» и «Овцевод» переведено 490 тыс. рублей на укомплектование колхозного стада, то же Трактороцентром - 84 тыс. 500 рублей. Кредиты задерживались вследствие того, что со стороны соответствующих областных организаций не предоставлялись своевременные отчеты по израсходованию средств.

2. Ассигнования НКЗемом [6] РСФСР на строительство скотных дворов для крупного рогатого скота в 2000 голов. Постройка упрощенных телятников на 5000 голов и на 700 голов крупного рогатого скота.

Имелась договоренность с НКЗ об увеличении средств на строительство при условии полной информации ХакОблЗУ [7] о ходе комплектования стада, а также строительство, последнее не провелось в жизнь, так как, несмотря на наше сообщение, ОблЗУ до сих пор не дало исчерпывающих данных.

3. Проведено Колхозцентром обследование работ ХакСоюза с вызовом в Москву представителя ХакСоюза.

4. Отпущено Москвой средств на подкрепление Госбанком в размере 375 тыс. рублей, а кроме того давались Госбанком твердые указания Новосибирску о выделении наличными деньгами Хакасскому Госбанку.

5. Отгружена автомашина для облисполкома, затем - запчасти. Другие вопросы, как-то: товароснабжения, рабочего питания, выделения снабжения Центросоюзом, нарсвязи, мелиорации, реорганизации Уйбатской станции - остаются в стадии разрешения, требуют дополнительного материала, а также уточнения контрольных цифр на 1932 г.

Представитель

Гедымин

[ГАРФ. Ф. 1235. Оп. 126. Д. 5. Л. 26-26об. Машинопись. Копия].

\section{Документ № 3 \\ Из отчета о работе Представительства Хакасской автономной области при ВЦИК за 1931 г.}

г. Москва

1932 г.

Основная задача - установление связей с центром и с местными краевыми органами. На первых порах необходимо было обеспечить поступление и систематизацию материалов, сведений, которые давали бы представление об области, ее естественных богатствах, состоянии хозяйства в настоящий момент.

Работа по связи с центром осуществлялась путем участия в проработке тех или иных вопросов, имеющих отношение к области, даче личных объяснений, справок, консультаций по отдельным вопросам. Другой стороной организационной работы была увязка своей работы с областными органами в смысле получения тех или иных указаний и в смысле своевременного освещения всех мероприятий и заметок центра, имеющих отношение к области. Эта работа осуществлялась путем постоянной письменной информации, посылкой копий всех ходатайств по отдельным вопросам, справок о прохождении в тех или иных инстанциях, а также путем выезда представителя в областной центр.

Западно-Сибирский край при его бурных темпах развития не мог в достаточной степени уделить внимание нуждам Хакасии.

$<\ldots>$ В настоящее время учащихся-хакасов в Москве - 25 человек. Руководство землячеством осуществляется представительством $<\ldots$. .

[ГАРБ. Ф. 1235. Оп. 126. Д. 5. Л. 30, 36-36об. Машинопись. Копия]. 


\section{Комментарии}

1. В 1923 г. Хакасии был предоставлен статус уезда, который в 1925 г. был преобразован в округ, а в 1930 г. - в Хакасскую автономную область (ХАО) в составе Западно-Сибирского края, с 1934 г. - в составе Красноярского края (Путеводитель по фондам Национального архива Республики Хакасия. - Абакан: Кооператив «Журналист», 2016. - 384 с.).

2. Высший Совет Народного Хозяйства РСФСР (BCHX) - орган управления народным хозяйством и государственных финансов РСФСР [Собрание узаконений... 1942: 66].

3. AО - имеется в виду автономная область Хакасии. По тексту упоминается и как ХАО.

4. Комитет УТБ ВЦИК - Комитет улучшения труда и быта был образован 30 мая 1930 г. из комиссии по улучшению труда и быта трудящихся женщин для общего руководства работой по массовому вовлечению женщин в социалистическое строительство, повышению культурного уровня и переустройству их быта. Местными органами комитета являлись одноименные комитеты при президиумах ЦИКов АССР краевых, областных, райисполкомах. Ликвидированы местными органами 10 июля 1932 г., с передачей функций секторам по работе среди женщин в составе орготделов президиума ВЦИКа и ЦИКов.

5. НКП - Народный комиссариат просвещения РСФСР (1917-1946 гг.).

6. НКзем (Наркомзем РСФСР) - Народный комиссариат земледелия РСФСР с 1917 по 1929 г. Образован в декабре 1929 г. на основании Постановления ЦИК СССР с сохранением ранее существовавших республиканских народных комиссариатов земледелия, краевых, областных и районных земорганов.

7. ХакОблЗО - Хакасский областной земельный отдел был образован 20 октября 1930 г. вместо Хакасского окружного земельного управления. Хакасский областной земельный отдел занимался организацией сельского хозяйства в области; руководил работой земельных органов на местах, выявлением площадей государственных земель, проводил профилактическую работу против заболеваний животных и организовывал агроучебу среди крестьянства (Путеводитель по фондам Национального архива Республики Хакасия. - Абакан: Кооператив «журналист», 2016. - С. 28, 245).

\section{Источники и литература}

Государственный архив Российской Федерации (ГАРФ).

Белозерова М. В. Деятельность представительств и уполномоченных по делам национальных меньшинств Наркомнаца в Южной Сибири (1920-1930-е гг.) / М. В. Белозерова // Известия Алтайского государственного университета. Сер. История. Политология. 2008. - № 4/4. - C. 16-21.

Карачакова О. М. О деятельности представительства Хакасской автономной области / О. М. Карачакова // Актуальные проблемы Саяно-Алтая и сопредельных территорий. - Абакан, 2005. - С. 240-242.

Мамышева Е. П. Опыт деятельности представительства Хакасской автономной области при Президиуме ВЦИК (1930-1938 гг.) / Е. П. Мамышева // Федерализм: Теория. Практика. История. - 2008. - № 4. - С. 173-182.

Мамылевв Е. П. Документы региональных архивов о деятельности представительств Ойротской и Хакасской автономных областей (1924-1938) / Е. П. Мамышева // Вестник Челябинского государственного университета. Сер. История. - 2009. - № 28(166). - Вып. 34. C. $96-101$.

Митюков М. А. Представительство Хакасской автономной области при Президиуме ВЦИК (1930-1938 гг.) / М. А. Митюков // Из истории Советской Хакасии. - Абакан: Хакниияли, 1986. - С. 42-49.

Путеводитель по фондам Национального архива Республики Хакасия. - Абакан: Кооператив «Журналист», $2016-384$ с.

Собрание узаконений и распоряжений правительства за 1917-1918 гг. № 5 от 16 декабря 1917 г. Отд. 1. - М.: Изд-во Управления делами Совнаркома СССР, 1942. 


\section{References}

Gosudarstvennyj arhiv Rossijskoj Federacii (GARF).

Belozerova $M$. $V$. Deyatel'nost' predstavitel'stv i upolnomochennyh po delam nacional'nyh men'shinstv Narkomnaca v Yuzhnoj Sibiri (1920-1930-e gg.) / M. V. Belozerova // Izvestiya Altajskogo gosudarstvennogo universiteta. Ser. Istoriya. Politologiya. - 2008. - № 4/4. - S. 16-21.

Karachakova O. M. O deyatel'nosti predstavitel'stva Hakasskoj avtonomnoj oblasti / O. M. Karachakova // Aktual'nye problemy Sayano-Altaya i sopredel'nyh territorij. - Abakan, 2005. S. 240-242.

Mamysheva E. P. Opyt deyatel'nosti predstavitel'stva Hakasskoj avtonomnoj oblasti pri Prezidiume VCIK (1930-1938 gg.) / E. P. Mamysheva // Federalizm: Teoriya. Praktika. Istoriya. 2008. - № 4. - S. 173-182.

Mamysheva E. P. Dokumenty regional'nyh arhivov o deyatel'nosti predstavitel'stv Ojrotskoj i Hakasskoj avtonomnyh oblastej (1924-1938) / E. P. Mamysheva // Vestnik Chelyabinskogo gosudarstvennogo universiteta. Ser. Istoriya. - 2009. - № 28(166). - Vyp. 34. - S. 96-101.

Mityukov M. A. Predstavitel'stvo Hakasskoj avtonomnoj oblasti pri Prezidiume VCIK (19301938 gg.) / M. A. Mityukov // Iz istorii Sovetskoj Hakasii. - Abakan: Hakniiyali, 1986. - S. 42-49. Putevoditel' po fondam Nacional'nogo arhiva Respubliki Hakasiya. - Abakan: Kooperativ «Zhurnalist», 2016-384 s.

Sobranie uzakonenij i rasporyazhenij pravitel'stva za 1917-1918 gg. № 5 ot 16 dekabrya 1917 g. Otd. 1. - M.: Izd-vo Upravleniya delami Sovnarkoma SSSR, 1942. 